\title{
Starting Well campaign is delivering on its commitment
}

The North-South divide is turned on its head when it comes to children's dentistry and attendance at an NHS dental practice. Dr Robin Mills, a specialist in paediatric dentistry and former British Society of Paediatric Dentistry (BSPD President), has used NHS Digital figures to produce a map (pictured) which shows that children in the North of England are more likely to have seen an NHS dentist in the last year. The map also shows that the Starting Well campaign is delivering on the commitment to improve children's oral health.

Dr Mills' map reflects dental attendance according to postcode areas. He has highlighted the 13 areas where the Starting Well programme to tackle poor dental attendance and poor oral health was introduced. His work shows there has been an overall improvement in the rankings of the 13 Starting Well postcode areas, indicating that the Department of Health initiative is working. The Dental Check by One (DCby1) campaign, which aims to get children seeing a dentist as their first teeth come through, was launched by BSPD in partnership with the Office of the Chief Dental Officer (OCDO) in 2017. Dental Check by One is integral to Starting Well which is now available as a core programme to all local authorities.

The NHS England figures analysed by Dr Mills are for March 2018 to March 2019 and so are only early signs at this stage. However, Dr Mills believes the figures are promising. He commented: 'It's very clear that of 13 Starting Well Local Authorities, 12 were in the top 50\% while seven were in the top $25 \%$ and none were in the lowest $25 \%$. This is an initiative which appears to be having an impact.

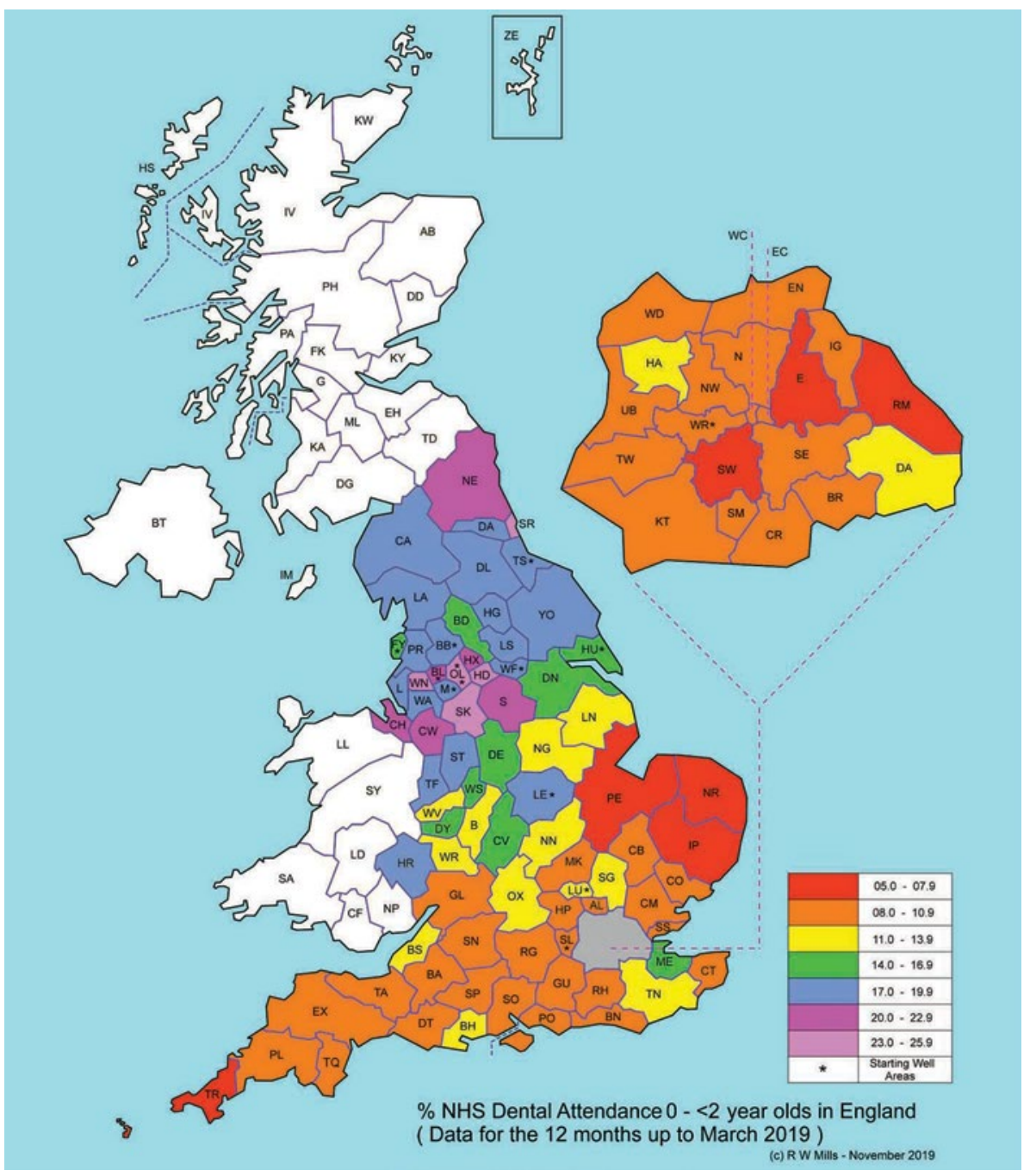

Notes: Postcode areas do not exactly match Local Authorities (LAs) but allow a clear graphic to be displayed in an A4 format. The map has, therefore, been compiled using postcode areas which in one case - Oldham - contains more than one LA. The map displays those postcode areas that contain a Local Authority where Starting Well has been introduced.

In addition to the Starting Well 13, the Department of Health launched Starting Well Core, a commissioning option which allows commissioners in England to give additional UDAs to practices to see the $0-2 \mathrm{~s}$.

'What we are also seeing is a NorthSouth divide with more children seeing an NHS dentist in the North West and
North East than in the South and even the Starting Well initiatives appear better in the North.'

\section{Honours, awards, appointments}

\section{PEC election}

The results for the BDA board (Principal Executive Committee) elections are now in for the 2020-22 triennium. The successful candidates are:

East Midlands and Central: Alison

Lockyer

London: Raj Majithia

Scotland: Laura Cross

South Eastern: Victor Chan

UK-wide: Tony Kilcoyne
All of them take up their mandate on 1 January 2020 alongside the ten other sitting members.

\section{Honorary patron}

Robert Kirschen is the new honorary patron of the British Orthodontic Society (BOS). Robert qualified from Guy's in 1975 and completed his orthodontic qualification in 1980 . He began working in specialist practice in 1982, and in 1985 was one of the first outside of London to fully convert to private practice. He has had a long relationship with the Royal London Hospital and was involved with postgraduate training up until 2010.

Robert has a long history with the BOS and also one of its forerunners, the BAO. He has served on BOS committees for many years and has been Chairman of both the Conference and Ethics committees. 